\title{
Produção de mudas de hortelã-japonesa em função da idade e de diferentes tipos de estaca
}

\author{
Scion production of mint in function of age and different types of cutting
}

\author{
Jorge Henrique Chagas ${ }^{\mathrm{I}}$ José Eduardo Brasil Pereira Pinto ${ }^{{ }^{*}}$ Suzan Kelly Vilela Bertolucci ${ }^{\mathrm{I}}$ \\ Felipe Hébia Nalon ${ }^{\mathrm{I}}$
}

\section{RESUMO}

O objetivo deste trabalho foi verificar a influência de diferentes idades e tipos de estacas na produção de mudas de Mentha arvensis L. Foram avaliados quatro diferentes tipos de estacas: estacas apicais retiradas da parte aérea; estacas retiradas da parte aérea mediana; estacas retiradas da ponteira do estolão e estacas retiradas da parte mediana dos estolões. Os diferentes tipos de estaca foram avaliadas com 25 e 40 dias de cultivo. Foram empregadas estacas com $4-5 \mathrm{~cm}$ de comprimento, enterradas $2 / 3$ no substrato comercial Plantmax $^{\circledR}$. Foram avaliados, nos dois períodos de enraizamento (25 e 40 dias) nos diferentes tipos de estaca na bandeja, a altura, o número de brotações, a biomassa seca da parte aérea e das raízes e a porcentagem de mortalidade. As estacas, após os períodos de enraizamento foram transplantadas para canteiro e vasos. Foi também determinada a porcentagem de mortalidade e a biomassa seca da parte aérea, das raízes e estolões, após um cultivo por 30 dias. Os resultados mostraram que as estacas apicais da parte aérea aos 25 dias e aos 40 dias após o plantio na bandeja apresentaram maior enraizamento e desenvolvimento da parte aérea e baixa porcentagem de mortalidade. Aos 25 dias, as estacas apicais da parte aérea se desenvolveram estando as mudas aptas ao transplantio para o campo. Aos 30 dias após o transplantio, as estacas apicais da parte aérea apresentaram maior crescimento, exceto para biomassa seca dos estolões.

Palavras-chave: Mentha arvensis L., planta medicinal, estaquia, propagação vegetativa.

\section{ABSTRACT}

The objective of this research was to verify the influence of different age and types of cuttings in the production of scion of Mentha arvensis L. Four different types of cuttings were evaluated: apical and medium cuttings (from aerial part); tip and medium cuttings (from rhizome part). The different types of cuttings were evaluated at 25 and 40 days of age. The cuttings used had 4-5cm long and covered with Plantmax ${ }^{\circledR}$ substrate to a depth of 2/3. Two rooting periods (25 and 40 days) from the different types of cuttings were evaluated: height, shoots number, aerial and roots dry biomass and percentage of mortality. The cuttings after the rooting period were transplanted to bed and pots. The mortality and the aerial part, roots and rhizome dry biomass were determined 30 days after being cultivated. The results showed that apical cuttings from aerial part at 25 and 40 days after being planted in trays had higher rooting, aerial part development and low mortality. At 25 days the aerial part developed and the scion was ready to be transplanted to field. Thirty days after transplanted apical cuttings from aerial part showed a higher growth, except for rhizome dry biomass.

Key words: Mentha arvensis L., medicinal plant, cutting, vegetative propagation.

\section{INTRODUÇÃO}

A hortelã-japonesa (Mentha arvensis L.) éuma planta medicinal e aromática da família Lamiaceae (Labiatae), também conhecida popularmente como mentajaponesa, vick, hortelã-do-brasil ou, simplesmente, hortelã. Tem hábito herbáceo rizomatosa, estolonífera, de caule quadrangular, com folhas opostas, ovaladas e serradas. Esta espécie possui propriedades etnoterapêuticas, caracterizadas como descongestionante nasal, e também pode ser utilizada no combate à flatulência, e em casos de náuseas e vômitos. De suas folhas, se extrai o óleo essencial rico em mentol (50 -70\%), de larga aplicação na indústria de alimentos, farmacêutica e de higiene (MARTINS et al., 1994).

IDepartamento de Agricultura, Universidade Federal de Lavras (UFLA), Lavras, MG, Brasil. E-mail: jeduardo@ufla.br.*Autor para correspondência. 
A propagação assexuada ou clonal é a mais utilizada na produção comercial de diversas espécies na horticultura, tendo como vantagens a manutenção de todas as características da planta matriz, a uniformidade nas mudas e a produção de produtos de alta qualidade, além de menor custo (HARTMANN et al., 2002).

Um dos fatores que tem limitado a expansão de culturas propagadas vegetativamente, segundo SEDIYAMA \& CASALI (1997), é a falta de material de plantio e, por isso, é recomendado o bom aproveitamento das mudas. Vários aspectos das mudas ainda não foram estudados e, se o foram, os resultados ainda não são conclusivos. Em razão disso, muitas informações disponíveis originam-se da experiência de produtores e de extensionistas. No entatnto, há que se ter cuidado porque o tipo e a qualidade do material de plantio determinam diferenças na velocidade de enraizamento, crescimento e, conseqüentemente, na produção e na extensão do ciclo vegetativo.

Diversos são os fatores que influenciam o enraizamento e a formação de mudas, entre eles, a posição da estaca no ramo, o grau de lignificação, a quantidade de reservas e a diferenciação dos tecidos, e o tipo de substrato, pelas suas características químicas e físicas. IKUTA (1998), estudando o enraizamento de estacas de marcela (Achyrocline satureioides), utilizou estacas da posição apical e lateral com quatro folhas completamente expandidas, em que as estacas da porção apical tiveram melhores resultados e maior vigor, durante todo o processo de enraizamento. SILVA et al. (2001), trabalhando com a espécie Mentha villosa, observou qu,e para a variável matéria fresca e seca dos brotos, as estacas de estolão e mediana ocorreram os maiores valores, não havendo diferença quanto ao peso seco das raízes.

Pouco se sabe sobre o uso de estaquia na propagação vegetativa de plantas medicinais . É de grande importância que sejam estabelecidas linhas de ação voltadas para o desenvolvimento de técnicas de manejo ou o cultivo (pesquisas fitotécnicas) das plantas com potencialidades terapêuticas e indústriais. Assim, neste trabalho, objetivou-se verificar a influência de diferentes tipos de estaca e idade na produção de mudas de hortelã-japonesa (Mentha arvensis L.), na região Sul do Estado de Minas Gerais.

\section{MATERIAL E MÉTODOS}

Os experimentos foram desenvolvidos em outubro a dezembro de 2006, no município de Lavras, região Sul de Minas Gerais, a 918m de altitude, latitude sul de $21^{\circ} 14^{\prime}$ 'e longitude oeste de $45^{\circ} 00^{\prime}$ GRW. O material botânico utilizado foi retirado de plantas matrizes. Foi feito o corte em bisel de quatro diferentes tipos de estaca: estacas da posição apical com apenas o primeiro par de folhas não retirado para não danificar o meristema apical (ponteiras, microestacas) e mediano da parte aérea da planta, ponteiras do estolão e medianas do estolão (Figura 1A). As estacas foram coletadas com 4 a $5 \mathrm{~cm}$ de comprimento. Após a coleta, realizada pela manhã, as estacas foram plantadas verticalmente em bandejas de isopor de 128 células, uma estaca por célula, contendo substrato comercial Plantmax ${ }^{\circledR}$ (Eucatex, São Paulo, SP), enterrando-se 2/3 da estaca. As bandejas com as estacas foram colocadas em bancadas com sombreamento de 70\% e irrigação, de modo que o substrato ficasse sempre úmido.

O delineamento utilizado foi o inteiramente casualizado, sendo dois períodos de enraizamento: 25 e 40 dias após o plantio dos quatro tipos de estaca: estaca apical e mediana da parte aérea da planta, ponteira e mediana do estolão, com cinco repetições, sendo cada parcela formada por seis estacas. O experimento foi instalado em casa de vegetação, avaliando as características biomassa seca total, da parte aérea e das raízes, da altura e do número de brotações.

A determinação da taxa de mortalidade dos diferentes tipos de estaca na bandeja foi realizada ao final de cada período de enraizamento, em um experimento com cinco repetições, cada repetição formada por 12 estacas. Para a determinação da taxa de mortalidade, no campo, dos diferentes tipos de estaca, foi instalado um experimento com cinco repetições, cada repetição formada por 10 estacas consideradas vivas após os períodos de enraizamento na casa de vegetação. Essas estacas foram transplantadas para canteiros a pleno sol no Horto Medicinal, com irrigações a cada dois dias e, após 30 dias, a contagem e a determinação da taxa de mortalidade destas estacas para os dois períodos de enraizamento.

Outro experimento também foi montado para avaliar a produção de biomassa seca total, da parte aérea, das raízes e dos estolões das mudas, provenientes dos diferentes tipos de estaca, após os períodos de enraizamento. Após aclimatização das mudas, essas estacas foram transplantadas para vasos com capacidade de dois litros, de forma aleatória, instalados no Horto Medicinal a pleno sol e irrigações a cada dois dias. Utilizou-se como substrato o Latossolo Vermelho-Escuro, retirado $30 \mathrm{~cm}$ abaixo da camada arável, cuja análise resultou: classe textural argilosa; $\mathrm{pH}=5,8 ; \mathrm{Ca}=0,8 \mathrm{cmol}_{\mathrm{c}} \mathrm{dm}^{-3} ; \mathrm{Mg}=0,2 \mathrm{cmol}_{\mathrm{c}} \mathrm{dm}^{-3} ; \mathrm{K}=$ 


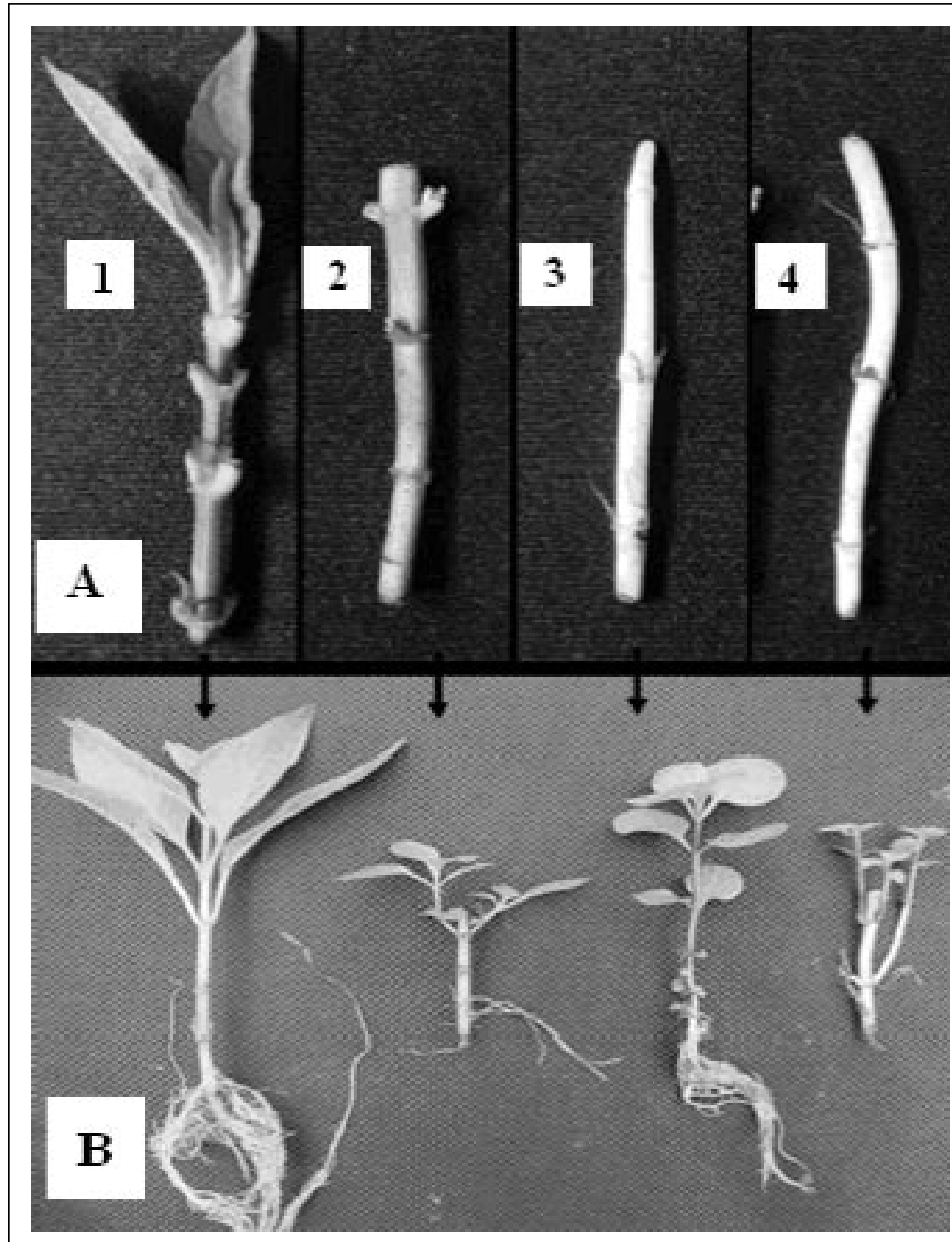

Figura 1 - A ilustra os diferentes tipos de estaca antes do plantio na bandeja: 1 - estaca apical da parte aérea, 2 - estaca mediana da parte aérea, 3 - estaca da ponteira do estolão e 4 - estaca da parte mediana do estolão. B ilustra o aspecto visual da parte aérea e do sistema radicular dos diferentes tipos de estaca após 25 dias de enraizamento.

$61 \mathrm{mg} \mathrm{dm}^{-3} ; \mathrm{H}+\mathrm{Al}=3,6 \mathrm{cmol}_{\mathrm{c}} \mathrm{dm}^{-3}$ e $\mathrm{P}=0,6 \mathrm{mg} \mathrm{dm}^{-3}$; matéria orgânica $=2,0 \mathrm{dag} \mathrm{kg}^{-1}$, e esterco bovino curtido na proporção de $50 \mathrm{~kg} \mathrm{~m}^{-3}$ cuja análise dos macronutrientes resultou: $\mathrm{N}=14 \mathrm{~g} \mathrm{~kg}^{-1} ; \mathrm{P}=3.77 \mathrm{~g} \mathrm{~kg}^{-1}$; $\mathrm{K}=31$ 7g. $\mathrm{kg}^{-1} ; \mathrm{Ca}=11,5 \mathrm{~g} \mathrm{~kg}^{-1} ; \mathrm{Mg}=3,0 \mathrm{~g} \mathrm{~kg}{ }^{-1} ; \mathrm{S}=2,2 \mathrm{~g}$ $\mathrm{kg}^{-1}$. A acidez do solo foi corrigida com calcário 40 dias antes do plantio. Este experimento constou de cinco repetições, sendo que a parcela foi formada por três vasos com uma estaca cada. A colheita da parte aérea e da raiz foi realizada 30 dias após o transplantio das estacas. As raízes, após lavadas em água corrente, e a parte aérea foram acondicionados em sacos de papel e secos em estufa com circulação forçada de ar, à temperatura de $60^{\circ} \mathrm{C}$, até peso constante. Adeterminação das biomassas secas foi feita em balança analítica digital.
As mudas dos diferentes tipos de estacas que foram transplantadas das bandejas para o canteiro e para os vasos passaram por um período de aclimatização de três dias, em bancada com 50\% de sombreamento. Depois de instalados os experimentos, o manejo e os tratos culturais como irrigações e capinas foram executados uniformemente entre os tratamentos, conforme a necessidade das plantas.

A análise estatística dos dados foi realizada utilizando-se o programa Sisvar ${ }^{\circledR}$ - versão 4.3 (FERREIRA, 1999). Os dados, referentes às taxas de mortalidade na bandeja e no campo, foram analisados transformados para $\sqrt{x+1}$. As médias entre os tratamentos foram submetidas à análise de variância, pelo teste de F e teste de Tukey a 5\% de significância. 


\section{RESULTADOS E DISCUSSÃO}

Após 25 dias do plantio nas bandejas, os diferentes tipos de estacas apresentaram diferenças significativas (Tabela 1 e Figura 1). As estacas apicais retiradas da parte aérea das plantas (Apical P.A.) apresentaram maior altura, maior biomassa seca da parte aérea (BSPA), maior biomassa seca das raízes (BSR) e, conseqüentemente, maior biomassa seca total (BST) do que os outros tipos de estaca. As estacas medianas, tanto da parte aérea quanto do estolão, apresentaram menor altura, BSPA e BST, assim como as estacas oriundas da ponteira do estolão. Quanto ao número de brotações, as estacas apicais da parte aérea apresentaram somente uma brotação, enquanto as outras apresentaram mais de duas brotações, estas não diferindo estatisticamente uma da outra. As estacas apicais (microestacas) da parte aérea, aos 25 dias, apresentaram melhor crescimento e rápido enraizamento e desenvolvimento da parte aérea, indicando que podem ser usadas na propagação vegetativa de $\boldsymbol{M}$. arvensis com sucesso e com maior rapidez (Figura 1).

Na avaliação dos 40 dias após o plantio nas bandejas, as estacas apicais da parte aérea (Apical P.A.) também apresentaram a maior altura, maior BSPA, BSR e BST, diferindo estatisticamente das demais (Tabela 1). As estacas medianas da parte aérea apresentaram o menor enraizamento e também a menor altura, junto com as estacas da parte mediana do estolão. As estacas provenientes do estolão apresentaram maior número de brotações, seguidas pela mediana da parte aérea e a apical da parte aérea, apresentando somente uma brotação. Esses resultados mostram que as estacas apicais da parte aérea continuaram o desenvolvimento do sistema radicular e da parte aérea, quase dobrando os pesos das biomassas secas na bandeja aos 40 dias. Já as estacas oriundas do estolão necessitaram de mais 15 dias de enraizamento para alcançar acúmulos de biomassa seca das raízes e parte aérea semelhantes aos acúmulos das estacas apicais da parte aérea com 25 dias de enraizamento, confirmando que a propagação vegetativa por meio de estacas apicais da parte aérea é mais rápida.

Pelas respostas observadas em relação aos acúmulos de biomassa seca das raízes, tanto aos 25 como aos 40 dias após o plantio das estacas nas bandejas (Tabela 1), nota-se que não há necessidade do uso de reguladores de crescimento para enraizamento, tornando a propagação mais barata.

Esses resultados foram semelhantes aos encontrados por SILVA et al. (2003), trabalhando com a mesma espécie, em que as estacas apicais da parte aérea apresentaram maiores valores de biomassa fresca e seca da parte aérea. Já EHLERT et al. (2004), trabalhando com alfavaca-cravo, observaram que a estaca mediana $(15 \mathrm{~cm})$ e apical com folha enraizaram melhor. No entanto, SOUSA et al. (2005) mostraram que a estaca basal $(15 \mathrm{~cm})$ foi a melhor para propagar alfavaca-cravo. IKUTA (1998) observou maior peso fresco e seco da parte aérea e enraizamento superior das estacas apicais 
de plantas de marcela (Achyrocline satureioides), em relação a estacas de outras partes da planta (estacas com $15 \mathrm{~cm}$ de comprimento). Esses resultados (superiores das estacas apicais da parte aérea), segundo LIONAKIS (1981), podem ser devido à presença de folhas, que garante a sobrevivência das estacas, tanto pela síntese de carboidratos por meio da fotossíntese, como pelo fornecimento de auxinas e outras substâncias importantes no processo de formação das raízes, estimulando a atividade cambial e a diferenciação celular. De acordo com TAIZ \& ZEIGER (2004), os locais de síntese de ácido indol acético (AIA) são, principalmente, os tecidos meristemáticos de partes novas da planta. Nas dicotiledôneas, é no ápice, ou seja, nas extremidades dos ramos, o local de síntese deAIA mais importante. TAIZ \& ZEIGER (2004) relatam que as auxinas promovem a formação de raízes laterais e adventícias, por agirem em grupos de células especiais do periciclo, estimulando-as a se dividirem. Essas células em divisão desenvolvem-se em meristema apical, tanto nas raízes adventícias quanto nas laterais. Assim, a ausência de folha na estaca mediana da parte aérea pode ter sido prejudicial a este tratamento.

O menor número de brotos das estacas apicais da parte aérea pode ser, segundo TAIZ \& ZEIGER (2004), devido à auxina, que regula a dominância apical, isto é, a dominância do ápice na inibição do crescimento de gemas axilares. Assim, a remoção do ápice caulinar (decapitação), em geral, resulta no crescimento de uma ou mais gemas laterais, explicando a maior brotação nas estacas medianas da parte aérea do que as apicais da parte aérea, devido à ausência da atividade auxínica, que foi removida juntamente com o ápice. As estacas de estolão podem ter apresentado maior brotação, por serem uma parte da planta induzida à multiplicação. Além disso, o corte impede a translocação da auxina nos estolões, fazendo com as gemas laterais se desenvolvam. Resultados divergentes foram encontrados por SILVA et al. (2001), em trabalho com propagação de Mentha villosa, em que as estacas apicais junto com as estacas de rizoma mostraram-se com maior número de brotos.

A taxa de mortalidade dos diferentes tipos de estaca com 25 e 40 dias após o plantio, nas bandejas e avaliadas no campo, apresentaram diferenças significativas (Tabela 2). A taxa de mortalidade nas bandejas, após 25 dias, foi menor nas estacas apicais da parte aérea em relação às medianas do estolão, porém, não diferiu em relação às da ponteira do estolão e mediana da parte aérea. Aos 40 dias, na bandeja, as mortalidades das estacas apicais da parte aérea e ponteira do estolão apresentaram as menores taxas (Tabela 2). Apesar de ocorrer mortalidade nas estacas medianas, esta percentagem não foi elevada. Talvez uma maneira para diminuir esta mortalidade fosse manter um par de folhas inteiras ou cortá-las pela metade. Segundo LIONAKIS (1981), a presença de folhas e as auxinas endógena na parte apical da brotação, que promovem a indução e um crescimento radicular mais rápido e intenso, garantem a sobrevivência das estacas. Estes resultados se opõem, em parte, aos resultados de SILVA et al. (2001), em que a taxa de mortalidade das estacas de estolões foi menor que as apicais e as medianas da parte aérea de plantas de Mentha villosa.

As estacas apicais da parte aérea, cultivadas no campo, com 25 dias de enraizamento, apresentaram menores taxas de mortalidade que as demais, evidenciando que as estacas mais bem enraizadas e com maior desenvolvimento da parte aérea sobreviveram melhor às condições mais severas de campo. No entanto, aos 40 dias de enraizamento, as estacas apicais da parte aérea somente apresentaram menores taxas mortalidade no campo em relação às medianas da parte aérea. Pode-se inferir que o maior tempo para o enraizamento das estacas, propiciou um

Tabela 2 - Taxa de mortalidade dos diferentes tipos de estaca: apical da parte aérea (Apical P.A.), mediana da parte aérea (Mediana P.A.), ponteira do estolão (Ponteira ES.) e mediana do estolão (Mediana ES.) de Mentha arvensis L., na bandeja e no campo, estacas com 25 e 40 dias de enraizamento.

\begin{tabular}{|c|c|c|c|c|}
\hline \multirow{2}{*}{ Tipos de estaca } & \multicolumn{2}{|c|}{ 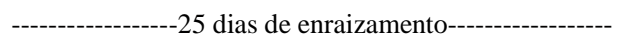 } & \multicolumn{2}{|c|}{ 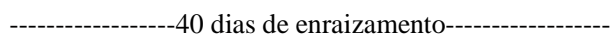 } \\
\hline & Mortalidade bandeja (\%) & Mortalidade campo (\%) & Mortalidade bandeja (\%) & Mortalidade campo (\%) \\
\hline Apical PA & $0,00 \mathrm{a}$ & $2,00 \mathrm{a}$ & 3,33 a & $2,00 \mathrm{a}$ \\
\hline Mediana PA & $6,66 \mathrm{ab}$ & $26,00 \mathrm{~b}$ & $28,33 \mathrm{~b}$ & $14,00 \mathrm{~b}$ \\
\hline Ponteira ES & $6,66 \mathrm{ab}$ & $16,00 \mathrm{~b}$ & 6,33 a & $6,00 \mathrm{ab}$ \\
\hline Mediana ES & $13,32 \mathrm{~b}$ & $16,00 \mathrm{~b}$ & $19,99 \mathrm{~b}$ & $6,00 \mathrm{ab}$ \\
\hline Média geral & 6,66 & 15,00 & 14,49 & 14,00 \\
\hline C.V. (\%) & 36,56 & 34,09 & 27,78 & 49,60 \\
\hline
\end{tabular}

Médias não seguidas de mesma letra na coluna diferem significativamente entre si pelo teste de Tukey a 5\% de significância. 
melhor desenvolvimento do sistema radicular e, conseqüentemente, uma menor taxa de mortalidade das estacas (Tabela 2).

Com 25 dias de enraizamento, pôde-se observar que as taxas de mortalidade na bandeja foram menores que as taxas de mortalidade no campo (Tabela 2), principalmente para as medianas da parte aérea e as dos estolões, o que pode ser devido aos menores acúmulos de biomassa seca, tanto das raízes quanto da parte aérea, evidenciando a boa formação das mudas por meio de estacas apicais da parte aérea. Já nas estacas com 40 dias de enraizamento, as taxas de mortalidade na bandeja foram maiores que as taxas de mortalidade no campo, principalmente nas estacas medianas da parte aérea e mediana do estolão (Tabela 2). Isso pode ser atribuído ao esgotamento das reservas pelas brotações sem o devido enraizamento, ocorrendo mais mortes de estacas até completar os 40 dias. As estacas que não morreram produziram biomassa seca das raízes e parte aérea suficiente para sobreviverem melhor no campo.

Os resultados do cultivo em vaso, por um mês, dos diferentes tipos de estaca com 25 dias de enraizamento, mostraram que as diferenças encontradas na fase de bandeja refletem no crescimento da planta após o transplantio (Tabela 3). As mudas formadas a partir de estacas apicais da parte aérea apresentaram maior BSPA e BST e as estacas retiradas da parte mediana da parte aérea apresentaram menores valores de biomassa. Com relação à biomassa seca das raízes, as estacas apicais da parte aérea, como da ponteira do estolão, mostraram melhor enraizamento do que as medianas. A produção de estolões, por meio da biomassa seca dos estolões (BSE), foi estatisticamente maior nas estacas da ponteira do estolão, seguidas pelas apicais da parte aérea e pelas medianas do estolão, com as medianas da parte aérea apresentando a menor produção. Os resultados mostraram que a boa formação da muda tem grande importância no cultivo. O melhor enraizamento e produção de biomassa seca das estacas da parte apical da parte aérea com 25 dias (Tabela 1) refletiram em maior crescimento e desenvolvimento da planta após o transplantio.

Já as mudas com 40 dias de enraizamento, provenientes de estacas apicais da parte aérea, apresentaram maior BST e BSR (Tabela 3). As estacas da ponteira do estolão apresentaram menor BST e BSR que as apicais da parte aérea e não diferiram quanto à BSPA, apresentando maior biomassa. Para a variável BSE, somente as estacas medianas da parte aérea apresentaram menor produção de estolões em relação aos demais tipos de estaca (Tabela 3). A produção de estolões é importante na cultura da menta na medida em que com a maior produção de estolões a cultura tende a ocupar melhor e mais rapidamente a aérea, principalmente após o primeiro corte, podendo influenciar a produção de biomassa seca da parte aérea da planta ao longo do tempo. A biomassa da parte aérea e da raiz é um atributo relacionado ao desempenho das mudas, pois, por meio das raízes, a nova planta

Tabela 3 - Biomassa seca da parte aérea (BSPA), biomassa seca das raízes (BSR), biomassa seca dos estolões (BSE) e biomassa seca total (BST) de mudas com 25 e 40 dias de enraizamento, provenientes dos diferentes tipos de estaca: apical da parte aérea (Apical P.A.), mediana da parte aérea (Mediana PA), ponteira do estolão (Ponteira ES.) e mediana do estolão (Mediana ES.) de plantas de Mentha arvensis L. após 30 dias de cultivo em vaso.

\begin{tabular}{|c|c|c|c|c|}
\hline \multicolumn{5}{|c|}{25 dias de enraizamento } \\
\hline Tipos de estaca & BSPA (g) & BSR (g) & BSE (g) & $\mathrm{BST}(\mathrm{g})$ \\
\hline Apical PA & 6,29 a & 3,67 a & $0,39 \mathrm{~b}$ & 10,36 a \\
\hline Mediana PA & $3,01 \mathrm{c}$ & $2,03 \mathrm{~b}$ & 0,09 c & $5,14 \mathrm{~d}$ \\
\hline Ponteira ES & $4,21 \mathrm{~b}$ & 3,07 a & $0,64 \mathrm{a}$ & 7,93 с \\
\hline Mediana ES & $3,67 \mathrm{bc}$ & $2,43 \mathrm{~b}$ & $0,29 \mathrm{~b} \mathrm{c}$ & $6,40 \mathrm{~b}$ \\
\hline Média geral & 4,29 & 2,80 & 0,35 & 7,45 \\
\hline CV (\%) & 11,93 & 12,05 & 35,44 & 18,05 \\
\hline Tipos de estaca & BSPA(g) & $\begin{array}{l}\text { le enraizan } \\
\text { BSR(g) }\end{array}$ & BSE(g) & BST(g) \\
\hline Apical PA & 7,34 a & $4,88 \mathrm{a}$ & $0,67 \mathrm{a}$ & $12,94 \mathrm{a}$ \\
\hline Mediana PA & $5,52 \mathrm{~b}$ & $2,99 \mathrm{c}$ & $0,27 \mathrm{~b}$ & 8,79 c \\
\hline Ponteira ES & 6,99 a & $3,97 \mathrm{~b}$ & 0,66 a & $11,63 \mathrm{~b}$ \\
\hline Mediana ES & $5,21 \mathrm{~b}$ & $3,31 \mathrm{c}$ & 0,61 a & 9,13 c \\
\hline Média geral & 6,26 & 3,78 & 0,55 & 10,62 \\
\hline CV (\%) & 8,74 & 7,78 & 22,98 & 5,74 \\
\hline
\end{tabular}

Médias não seguidas de mesma letra na coluna diferem significativamente entre si pelo teste de Tukey a 5\% de significância. 
transloca, para a parte aérea, os nutrientes para serem transformados em biomassa vegetal (CHAVES et al., 2004). Em trabalho que teve como objetivo avaliar a capacidade produtiva da araruta “Comum”, utilizando três tipos de propágulos formados por diferentes partes dos rizomas (base, ponta e meio), ZÁRATE \& VIEIRA (2005) observaram que as mudas formadas a partir das diferentes partes do rizoma influenciaram a produção de biomassa seca de rizomas (parte comercial da planta) e de raízes, não diferindo quanto à parte aérea.

De modo geral, os resultados mostraram que as estacas que se desenvolveram bem e tiveram maiores acúmulos de biomassa seca na bandeja também apresentaram o mesmo comportamento após o transplantio, o que mostra a importância de se produzir uma muda de qualidade.

\section{CONCLUSÕES}

A Mentha arvensis L. pode ser propagada tanto pelas estacas da parte aérea como por estacas retiradas dos estolões. Porém, estacas apicais retiradas da parte aérea demonstraram maior vigor e sobrevivência, estando aptas ao transplantio para o campo aos 25 dias de enraizamento.

\section{AGRADECIMENTOS}

À Coordenação de Aperfeiçoamento de Pessoal de Nível Superior (CAPES) e ao Conselho Nacional de Desenvolvimento Científico e Tecnológico (CNPq), pela concessão das bolsas de estudos, e à Fundação de Amparo à Pesquisa do Estado de Minas Gerais (FAPEMIG), pelo auxílio financeiro.

\section{REFERÊNCIAS}

CHAVES, F.C.M. et al. Propagação vegetativa de cipó-alho utilizando estacas de diversos diâmetros. In: CONGRESSO BRASILEIRO DE OLERICULTURA, 44., 2004, Campo Grande, MS. Anais... Campo Grande: Sociedade de Olericultura do Brasil, 2004. V.22, n.2, Supl.2. CD-ROM.
EHLERT, P.A.D. et al. Propagação vegetativa da alfavacacravo utilizando diferentes tipos de estacas e substratos. Horticultura Brasileira, Brasília, v.22, n.1, p.10-13, 2004.

FERREIRA, D.F. Sistema de análises estatísticas. Sisvar ${ }^{\circledR}$ - versão 4.3. Lavras: UFLA, 1999. 1 CD.

HARTMANN, H.T. et al. Plant propagation: principles and practices. 7.ed. New Jersey: Prentice-Hall, 2002. 880p.

IKUTA, A.R.Y. Estudos sobre propagação de marcela, Achyrocline satureioides (Lam.) DC., Compositae. In:

Plantas medicinais, aromáticas e condimentares: avanços na pesquisa agronômica. Botucatu: UNESP, 1998. V.1, p.165191.

LIONAKIS, S.M. Physiological studies on growth and dormancy of the kiwifruit plant (Actinidia chinensis Planch). 1981. 138f. Thesis (PhD, Plant Physiology) University of London, London.

MARTINS, E.R. et al. Plantas medicinais. Viçosa: UFV, 1994. 220p.

SEDIYAMA, M.A.N.; CASALI, V.W.D. Propagação vegetativa da mandioquinha-salsa. Informe Agropecuário, Belo Horizonte, v.19, n.190, p.24-27, 1997.

SILVA R. et al. Propagação vegetativa de estacas de hortelã japonesa (Mentha arvensis Huds) em bandejas multicelulares. In: CONGRESSO BRASILEIRO DE OLERICULTURA, 43. 2003, Recife, PE. Anais... Recife: Sociedade de Olericultura do Brasil, 2003, v. 21, n. 2, Suplemento CD-ROM.

SILVA R. et al. Propagação vegetativa de estacas de hortelãrasteira (Mentha villosa Huds) em bandejas multicelulares. In: CONGRESSO BRASILEIRO DE OLERICULTURA, 41., 2001, Brasília, DF. Anais... Brasília: Sociedade de Olericultura do Brasil, 2001. V.19, n.2, Supl. CD-ROM.

SOUSA, P.B.L. et al. Propagação vegetativa de Ocimum gratissimum L. em diferentes substratos. Revista Brasileira de Plantas Medicinais, Botucatu, v.8, n.1, p.39-44, 2005.

TAIZ, L.; ZEIGER, E. Fisiologia vegetal. 3.ed. Porto Alegre: Artmed, 2004. 719p.

ZÁRATE, N.A.H.; VIEIRA, M.C. Produção da araruta “comum” provenientes de três tipos de propágulos. Ciência e Agrotecnologia, Lavras, v.29, n.5, p.995-1000, 2005. 